Western University

Scholarship@Western

Law Publications

Law School

$11-2010$

\title{
From Music Tracks to Google Maps: Who Owns Computer-generated Works?
}

Mark Perry

The University of Western Ontario, mperry@uwo.ca

Thomas Margoni

The University of Western Ontario, tmargoni@uwo.ca

Follow this and additional works at: https://ir.lib.uwo.ca/lawpub

Part of the Computer Law Commons, and the Intellectual Property Law Commons

Citation of this paper:

Perry, Mark and Margoni, Thomas, "From Music Tracks to Google Maps: Who Owns Computer-generated Works?" (2010). Law Publications. 27.

https://ir.lib.uwo.ca/lawpub/27 


\author{
From music tracks to Google maps: \\ who owns Computer-generated Works? \\ Mark Perry and Thomas Margoni* \\ Faculty of Law, The University of Western Ontario, London, Ontario, Canada
}

\begin{abstract}
Increasingly the digital content used in everyday life has little or no human intervention in its creation. Typically, when such content is delivered to consumers it comes with attached claims of copyright. However, depending on the jurisdiction, approaches to ownership of computer-generated works vary from legislated to uncertain. In this paper we look at the various approaches taken by the common law, and the legislative approach take in the United Kingdom.
\end{abstract}

\title{
Keywords:
}

Computer-generated works; copyright, authors and ownership; legislative and common law approaches

\section{Introduction}

Globally, ${ }^{1}$ the default situation is that the author of a work is also its first owner ${ }^{2}$ - a general rule that has never gave rise to significant controversy. There are specific situations where the creative workflow follows some specific course, such as work for hire, joint authorship, cinematographic works, and so forth, where the author - the person who created the work - is not its owner. Even in these cases, however, it is typically a "person" that is the author, and a person or business that is the owner. What if the creator of a work is not a person, but a machine and/or algorithm? This article analyses the status of authorship and ownership for the creation of works by non-human actors, with particular attention to common law countries, and recommends which approaches should best be pursued in those jurisdictions, such as Canada, where the issue has yet to be settled.

Over the last two decades there has been the propagation of increasingly sophisticated machines and software that are able to perform work that until recently was not imaginable, especially those tasks that today are absent of human intervention. However, there is the doubt that a machine could be creative and thus deserving copyright protection, although today the creations of commonly used software are highly sophisticated and not solely those that would be seen as cutting edge research or areas still hotly debated, such as Artificial Intelligence (A.I.). The outputs of such computer systems affect the everyday life of millions of people. For example, imagine that you are visiting your cousin. You know her address but you forget the directions, so you run an inquiry on Google maps (or Ovi maps, or any other similar service) to have a precise guide of your trip. ${ }^{3}$ Since your cousin lives in a very attractive naturalistic area, you select the "terrain" option, and you receive a detailed route that should get you there in 25 minutes. After one hour of driving (the highway is closed and your map almost useless) you are driving at $55 \mathrm{mph}$ and you get caught by a speed control camera for speeding (without your knowledge at the time). You arrive a bit late at house, which is just in front of a museum. Before entering, you notice a van - driving slowly - crossing the intersection (the car has some weird tripod on it, and there is a street-map inscription on the doors). This simple scenario illustrates some situations that are much more common than one may have thought with examples of works produced by machines where the role played by humans is at least very remote. The satellites pictures of the terrain, the picture of your car speeding, the recordings by the security cameras of

Mark Perry is Associate Dean Research, Graduate Programs, and Operations in the Faculty of Law, and Associate Professor of Computer Science, Faculty of Science. Thomas Margoni is a Post Doctoral Fellow at the Faculty of Law, and Assistant Professor of Computer Science, Faculty of Science. The authors thank Constance Yoo (Law Class of 2013) for her research assistance and the Law Foundation of Ontario for its support.

1 See art. 6bis Berne Convention for the Protection of Literary and Artistic Works, Sept. 9, 1886 (revised July 24, 1971 and amended 1979) [Berne Convention].

2 For example, Copyright, Design and Patents Act, U.K. 1988 (c. 48), c. 1, s. 11; Canadian Copyright Act, R.S.C. 1985, c. C-42, s. 13 [Canadian Copyright Act].

3 A survey in 2008 puts map searches at over 300 million per day; see http://searchenginewatch.com/3630718. 
the museum, the pictures (and wireless network data) gathered by the street-map car. The role played by a human component is questionable, marginal, and sometimes even completely absent. Where is the author? Where the expression of human intellect? Where are the choices and decisions that artists usually take when creating their works, in pictures or film, where the utmost objective is to describe facts as accurately as possible? In all these cases, there is no 'creative spark' for the situation, no authorial contribution, no "art" provided in the realisation of the product. The role played by the human component is purely mechanical, such as deciding some time in advance of activation of the code for the time interval of the shutter (take a picture of the earth surface every 5 seconds), or point the speeding control camera as it focuses on the right segment of road (the camera is activated by a sensor that triggers when the speed limit is overcome), or of the entry of the museum (and it records basically everything it happens), or again to decide the right height of the tripod as to take the pictures of the street and buildings as accurately as possible. Even these considerations are largely determined by the physical environment of operation and the requirements of the output. Indeed, the goal of such representations of reality is to be as adherent to reality as possible - to simply and purely describe the facts, without more. It would be undesirable for an "artistic" operator to paint the image of the speeding car in a different colour, or to change the font or the number-plate of the car, in order to have a final result that would be aesthetically more pleasant. Indeed, it might be! However, the scope of such kind of information is not that - it is to purely describe the facts as already existing in nature, as accurately as possible. In such cases there is no space for any creative, original, authorial intervention that might compromise such result. Nonetheless, we are frequently presented terrain maps, car and street pictures, and films, that at first sight reveal nothing about their artificial genesis, but which at the same time are accompanied with claims of copyright.

In order to establish who should be taken as the author of a work that has been computer-generated without direct "human intervention", concepts such as "work of authorship" and "author" are of pivotal importance. In those legal systems where a work needs to be creative to qualify for protection it might be argued that only a human is capable of authorship. Creativity, especially under the civil-law tradition, is a concept that is strongly connected to the person, and may be seen as an emanation of the author's personality. To discuss whether a computer could be creative is very compelling, but is not going to be discussed here. A.I. seem to represent the philosopher's stone of computing systems, able to transform a very complicated series of operations into "something more". In the field of A.I. the traditional test for satisfying "humanisation" has been the situation where an interrogator is not able to distinguish a human respondent from a machine respondent on the sole basis of the given answer. In such a case it is said that the machine has passed the Turing test, and thus "is able to think". Alan Turing proposed the test (in a more formal way) more than half a century $\mathrm{ago}^{4}$. Of course, the test has been widely referred and widely criticised, though it imposed itself as a reference point in the field of A.I. That being said, this article is not concerned with A.I. and we will maintain our focus on the current state of the art in computer science, which is nonetheless highly advanced, so much that those jurisdictions where originality does not rely on creativity offer us the theoretical background to potentially accept that a non-human, such as a computer, can be an author. Interestingly, legislators in a number of such jurisdictions, notably the United Kingdom, South Africa, New Zealand (and to some extent also Australia), felt the necessity to state in their Copyright Acts that in the case of Computer-generated Works (CGW) the author shall be "the person by whom the arrangements necessary for the creation of the work are undertaken" . Australia represents a peculiarity, as it does not have such wording in the Copyright Act, however it can be read in the 1994 Report produced by the Copyright Law Review Committee on Software Protection ${ }^{6}$. The wording of the Copyright Act - where it says that only an Australian citizen or a person living in Australia qualifies for authorship ${ }^{7}$, and court decisions explicitly neglecting computers as being capable of producing copyright works ${ }^{8}$, clearly exclude authorship by nonhumans. After all, the role of creativity in Australian copyright law is not completely neglected ${ }^{9}$.

Also noteworthy within a jurisdiction where creativity is clearly accepted and non-human authorship excluded is the U.S.A. CONTU Final Report on copyright protection of software, even though it does not

4 See A. Turing, Computing Machinery and Intelligence, (1950) 59 Mind, 433

5 See Copyright, Design and Patents Act, U.K. 1988 (c. 48), c. 1, s. 9(3); South Africa Copyright Act, No. 98 of 1978 , s. 1; Copyright Act (N.Z.), 1994/143, s. 5(2)(a).

6 See also Australia Copyright Law Review Committee Report on Computer Software Protection 1994 (Cth.), s. 13.11-13.23.

7 See Australian Copyright Act 1968, sec. 32

8 See Telstra Corporation Limited v Phone Directories Company Pty Ltd [2010] FCA 44, at 5.2.3

9 See IceTV Pty Limited v Nine Network Australia Pty Limited, [2009] HCA 14 (22 April 2009), at 47. 
distinguish explicitly between computer-assisted and computer-generated works, ${ }^{10}$ and the report was drafted much before Feist. ${ }^{11}$

\section{Computer-generated Works}

Computer-generated Works (CGW) can be defined as those works that are created in total absence of any human intervention at the time of the creation of the work. We need to distinguish between two potentially confusing types: works that are created through the assistance of a computer, and works that are computer-generated. Computer-assisted works do not warrant specific categorisation, any more than other works, such as (pen-assisted) literary works, or (camera-assisted) films. In almost any manifestation of human creativity, the author is assisted by, or is using some tool that facilitates or improves her task - the exception being works performed "live" that are not fixed and which in some jurisdictions might lack protection due to the lack of fixation, such as in the United States ${ }^{12}$ or Australia, ${ }^{13}$ just to name a few. Therefore, despite attracting clear statutory ("computer-generated in relation to a work, means that the work is generated by computer in circumstances such that there is no human author of the work"14) and judicial ("II]n my view a work only qualifies as having been computer-generated if it was created by a computer in circumstances where there is no human author of the work. If there is a human author the work is computerassisted and not computer-generated" ${ }^{15}$ ) definitions, in the category of CGW there is no direct human intervention mainly for a logical reason: if there was human intervention, this would be no special category, but rather the usual way of creating works by humans.

Despite the blossoming production of CGW, such issues have received little attention globally ${ }^{16}$, and none in Canada. The Canadian situation has no specific legislation on the status of a CGW, and there have been no cases on the point. However, what can be seen as a new standard of originality recently developed by the Supreme Court of Canada (SCC), could give some guidance in addressing the issue. ${ }^{17}$ Taking as a starting point under Canadian law the parameters for a protectable work, including the requirements for originality and levels of creativity, it is possible to discuss who its author is both under a creativity and a utilitarian analysis. We will conclude with some final remarks and recommendations.

10 See Final Report of the National Commission on New Technology Uses of Copyright Works, Pub. L. No. 93-573, § 3976, 2 Stat. at 45 (1974) [CONTU].

11 See Feist Publications, Incorporated v. Rural Telephone Service Company, Incorporated [1991] 499 U.S. 340111 S. Ct. 1282; 113 L. Ed. 2D 358.

12 See Copyright Act of 1976, Pub. L. No. 94-553, § 101, 90 Stat. 2541 (codified as amended at 44 U.S.C. $\S \S 505 / 7$ 2113; 18 U.S.C. $§ 2318$ [U.S. Copyright Act].

13 See IceTV Pty Limited v Nine Network Australia Pty Limited [2009] HCA 14 at 102 and 103; Telstra Corporation Limited v Phone Directories Company Pty Ltd [2010] FCA 44 at 20.

14 See Copyright, Design and Patents Act, U.K. 1988 (c. 48), c. 1, s. 178; Copyright Act (N.Z.), 1994/143, s. 2(1).

15 See for example Haupt v Brewers Marketing Intelligence (Pty) Ltd [2006] SCA 39 (RSA) at 31; see also L. Tong, Copyright and computer programs, computer-generated works and databases in South Africa, in E.I.P.R. 2006, 28(12), 625-628.

16 For a brief but accurate analysis of the international and EU legislative framework and how the CGW found its way into English law, see R.J. Hart, Intellectual property concepts: Authorship and originality - Author's own intellectual creation - Computer generated works, in The Computer Law \& Security Report, Volume 9, Issue 4, July-August 1993, 164-166; For the U.S. system see A. Miller, Copyright Protection for Computer Programs, Databases, and Computer-Generated Works: Is Anything New Since CONTU?, 106 Harvard Law Review 1977 (1993); P. Samuelson, Allocating ownership rights in computer-generated works, 47 U. Pitt. L. Rev. 1185, 1224ss; D. Glasser, Copyrights in Computer-Generated Works: Whom, if anyone, do we reward?, 2001 Duke L. \& Tech. Rev. 0024; In England, under the old Copyright Act of 1956, J. Appleton, Computer-generated output - the neglected copyright work, in E.I.P.R. 1986, 8(8), 227-228; S. Chalton, The legal protection of information comprised in software and database, in Computer Law \& Security Report, Volume 16, Issue 5, 1 October 2000, 291-294; See also, with scepticism toward the category, W.R. Cornish, Intellectual Property, London, 2003 at 1340. Regarding court decisions, particularly relevant in England: Nova Productions Ltd v Mazooma Games Ltd \& Ors Rev 1 [2006] EWHC 24 (Ch) (20 January 2006), (appealed at [2007] EWCA Civ. 219); In South Africa Haupt v Brewers Marketing Intelligence (Pty) Ltd [2006] SCA 39 (RSA); in Australia Telstra Corporation Limited v Phone Directories Company Pty Ltd [2010] FCA 44, at 5.2.3.

17 See CCH v. Law Society of Upper Canada [2004] 1 S.C.R. 339, 2004 SCC 13, 236 D.L.R. (4th) 395, 30 C.P.R. (4th) 1, 247 F.T.R. $318[\mathrm{CHH}]$. 


\section{Works and Authors}

The Canadian Copyright Act requires that for a work to qualify for protection it must be original, though originality is not defined by the Act. ${ }^{18}$ Such a situation is common to many legal systems. There are two different schools of thought on the issue of originality in common law countries: that which requires a spark of creativity and that of "industriousness" (also referred to as "sweat of the brow"). An example of a jurisdiction with the creativity test is the United States of America, where the Supreme Court has clearly stated that a modicum of creativity is a requirement in order for a work to qualify for copyright protection ${ }^{19}$ and that "there can be no valid copyright in facts [is universally understood]. The most fundamental axiom of copyright law is that [499 U.S. 340, 345] [n] author may copyright his ideas or the facts he narrates" ${ }^{20} \mathrm{~A}$ typical example of the other school of thought, which also historically represents the traditional approach in common law countries, is the United Kingdom where for a work to qualify for protection there needs to be the execution of "skill, judgement and labour" ${ }^{21}$ or "labour, skill, and capital", ${ }^{22}$ or "intellectual skill and brain labour". ${ }^{23}$

In Canada the situation had been debated until recently with the Courts showing some support for both approaches.$^{24}$ In 2004 the SCC, in $\mathrm{CCH} v$. Law Society of Upper Canada $(\mathrm{CCH}),{ }^{25}$ had the opportunity to shed some light on the originality requirement. However, analysis of the same decision has given rise to both a creativity based approach, ${ }^{26}$ and an industriousness one. ${ }^{27}$ Nevertheless, facts are clearly not protected.$^{28}$ In the decision the SCC recognizes the historical and conceptual existence of the two different and somewhat opposite approaches, and by criticizing the drawbacks of both, proposes a new standard that should place itself in between of the two. The SCC believes that the new standard will catch the advantages of a more than a industrious model, but without requiring a too high standard like that of creativity.

The intent of finding a compromised solution that could potentially reconcile two opposite approaches in the same legal tradition is laudable, but such an approach brings with it the potential to further blur the distinction, as this has proven to be the case. Nevertheless, what is certain, is that in $C C H$ the SCC rejected a plain application of a sweat of the brow standard:

"I conclude that the correct position falls between these two extremes. For a work to be 'original' within the meaning of the Copyright Act, it must be more than a mere copy of another work". ${ }^{29}$

It also explicitly denies creativity:

"At the same time, it needs not be creative, in the sense of being novel or unique. What is required to attract copyright protection in the expression of an idea is an exercise of skill and judgement". ${ }^{30}$

It is interesting to note that the SCC speaks of skill and judgement, without reporting a third term usually associated with the other two: labour. The Supreme Court adds that

"skill [...] mean[s] the use of one's knowledge, developed aptitude or practised ability in producing the work" and "judgement [...] mean[s] the use of one's capacity for discernment or ability to form an opinion or evaluation by comparing different possible options in

18 See Canadian Copyright Act, R.S. C. 1985, c. C-42, s. 5(1).

19 See Feist Publications, Incorporated v. Rural Telephone Service Company, Incorporated [1991] 499 U.S. 340111 S. Ct. 1282; 113 L. Ed. 2D 358.

20 See Harper \& Row, Publishers, Inc. v. Nation Enterprises, [471 U.S. 539, 556] (1985).

21 See Ladbroke (Football) Ltd v William Hill (Football) Ltd [1964] 1 WLR 273 (HL).

22 See W.R. Cornish, Intellectual Property, London, 2003 at 10-04; K. Garnet - J. Rayner James - G. Davies, Copinger and Skone James on copyright, $14^{\text {th }}$ Ed. at 3-85.

23 Walter v. Lane [1900] AC 539, decision reached before a statutory requirement of originality was inserted in the Copyright Act.

24 For the creativity approach see Tele-Direct v. American Businesses (1997) 76 C.P.R. (3d) 296; for the industriousness approach see $U \& R$ Tax Services Ltd. v. H \& R Block Canada Inc., (1995), 62 C.P.R. (3d) 257.

25 See above note 17.

26 D. J. Gervais, Canadian Copyright Law Post-CCH, (2004) 18 I.P.J. 131.

27 The Supreme Court of South Africa, but with remarks, see Haupt v. Brewers Marketing Intelligence Ltd [2006] SCA 39 (RSA), at n. 35.

28 "[...]in Canada, as in the United States, copyright protection does not extend to facts or ideas but is limited to the expression of ideas", see CHH, supra note 17 at 22.

29 See $C H H$, supra note 17 at 16.

30 Id. Why the Court employs terms such as novelty and uniqueness that are typical of the different field of patent law, remains a mystery. 
producing the work". 31

Thereby, the Court concludes that the exercise of skill and judgement involves intellectual effort, since it cannot be as trivial as a "purely mechanical exercise".

Whether a CGW could qualify for protection must be considered in light of the reported originality requirement. However, the task is not easy since the very same SCC declares that its standard is placed somewhere between the two traditional ones. For the industriousness model, minimal requirements for skill, judgement and labour form a standard that could be reasonably achieved by a computer. Of course such a computer should base its computational activity in a series of instructions that have been imparted in the first instance by a human. However, after the programming activity, the role played by the human in the creation of the CGW is negligible. In some cases, for instance those musical creations based on statistical analysis of a specific kind of music (classical, pop, jazz) performed by a computer, and where such creations are not manifestly distinguishable from a human created one, ${ }^{32}$ it seems arguable that the CGW could satisfy the requirement of originality as previously defined. The same holds true, for example, in the case of the films recorded by a security camera, that records everything that happens in their area of surveillance: in such a case the only human activity has been to determine the range of the camera and to turn it on. Though, at first sight, the images produced might look like those recorded by a human operator.

The same test should be performed for those jurisdictions where originality involves creativity. In those cases, the problem cannot be definitively and generally addressed without a proper definition of creativity. Nonetheless such a philosophical and epistemological problem is out of the scope of this paper. What we can say is that, at least in European continental jurisdictions, creativity is intimately connected with the type of protection offered: not against unauthorized copies, but in favour of authors. Droit d'auteur, Urheberrecht, Derecho de autor, are the labels used in civil law countries, being one of the major features of these systems, to protect authors with both economic and moral rights. "[Moral rights] treat the artist's oeuvre as an extension of his or her personality, possessing a dignity which is deserving of protection" ${ }^{33}$ For instance, one of the moral rights commonly (but not always) granted is that of withdrawal: that is, if the author feels one of her works may seriously prejudice her honour and reputation (because, for example, she lately has changed her view on a specific matter, or she has embraced a new style) she can "withdraw" all the copies from the market. The protection of the author's personality is apparent. It should be noted that (with variations from country to country) moral rights are usually not transferable, many times not waivable, and in some cases (France, Italy, for instance) perpetual: their enforcement is left to the heirs of the author, and ultimately to the State. In addition, in those countries that embrace a "monistic" approach (most notably Germany) not even the economic rights may be assigned. The only way to let others use one's work is through a licence. Copyright assignments are not envisioned by such systems. Additionally, in civil law countries, when dealing with copyright issues, commentators use wording that somehow mirrors the relationship between parents and sons such as, for instance, "umbilical cordons" ${ }^{34}$ - again a strong manifestation of how the author's right is strongly connected with the person (and the personality) of the author, not only on the legislative level, but also on the cultural one.

A partial conclusion that we may draw is that the concept of creativity, at least in civil law countries, has been drafted and has grown along with direct human intervention. In the U.S. the situation is similar in the sense that it has explicitly excluded authorship by non-humans ${ }^{35}$ It is worth noting that in such a creativity-based system even creative machines do not qualify for copyright registration: "In order to be entitled to copyright registration, a work must be the product of human authorship. Works produced by mechanical processes or random selection without any contribution by a human author are not registrable" ${ }^{36}$ Following a period of uncertainty, Australia has recently expressed opinions along the same lines. ${ }^{37}$

Since we are looking for an author in the absence of humans, in those systems where creativity is a

31 Id.

32 See M. Hoeberechts \& J. Shantz, Real-Time Emotional Adaptation in Automated Composition, 2009 Conference Proceedings Audio Mostly, Glasgow, Scotland, September 2-3 2009. A demonstration of this kind of software is available at: http://publish.uwo.ca/ mhoebere/amee/AMEEDemo.MPG .

33 See Théberge v. Galerie d'Art du Petit Champlain Inc., [2002] 2 S.C.R. 336, 2002 SCC 34, at 15 [Théberge].

34 See for example V.M. De Sanctis, I Soggetti del diritto d'autore, 2d ed. (Milano: Giuffré, 2004).

35 See C.A. Carson, Laser bones: Copyright issues raised by the use of information technology in archaeology, (1997) 10 Harv. J. Law \& Tec 281 at 298, n. 99.

36 See Compendium II of copyright Office Practices. §503.03(1) (1984) [Compendium II]; It must be recalled that the Compendium has not force of law, and is meant as an internal manual for Copyright Office staff.

37 See Telstra Corporation Limited v Phone Directories Company Pty Ltd [2010] FCA 44, at 5.2.3; see also Australia Copyright Law Review Committee Report on Computer Software Protection 1994 (Cth.), s. 13.11-13.23. 
requirement for copyright protection, arguably computers may not be deemed authors. Otherwise, if we had a computer system that can pass a test that allows it to substitute for a human (for example the Turing test cited above) $)^{38}$ then it would be arguable that such a computer system might be creative in its own right. This conclusion seems to be supported by our opening observation on originality, i.e. in those jurisdictions where the spark of creativity is not required such that actions performed by a particularly sophisticated computer are potentially capable to produce a work of authorship, it has been legislated that the author should be deemed to be the person who took the steps necessary for running the program (such as in the United Kingdom, South Africa, New Zealand, and - limited to the Copyright Law Review Report - Australia). Similar provisions have not been observed in creativity based traditions.

Whilst shedding some light on the concept of creativity applied to computers this is not conclusive in establishing the situation under Canadian law, since it is not easy to define the requirement for copyright protection in terms of creativity after $\mathrm{CCH}$ with any certainty. Although the SCC explicitly declared that creativity is not required, the definition of skill and judgement and the omission of labour are closely defined by the SCC to activities performable only by humans: “...the use of one's knowledge, developed aptitude or practised ability in producing the work and ... the use of one's capacity for discernment or ability to form an opinion or evaluation by comparing different possible options in producing the work". ${ }^{39}$

It could be argued that some kinds of A.I. system (i.e. machine that passed the Turing test) will be able to perform similar activities, which are likely to be ontologically superior to the definition of "purely mechanical exercise". However, the impression left by the SCC that it was thinking exclusively in human activities, even without mentioning them, permeates the whole decision. In fact, it could well be that the court did not feel the need to specify the word "human", because it is present implicitly in the definition it gave. A great deal of speculation, though, is recognizable in the present assumption, and it is not possible to completely remove it until the SCC gives its opinion on that specific matter.

Accordingly, it is admittedly not possible to establish or negate whether a machine could be taken as the author of a CGW under Canadian law basing purely on the analysis of the concept of creativity (or its absence) as recently defined by the SCC.

\section{Who should be rewarded?}

From a utilitarian perspective, the question is: who should be rewarded in order to foster a more (scientific and artistic) efficient and wealthy society? The usual suspects are: a) the author of program; b) the user of the program; c) the program; and d) none. Such four-fold partition fails to enumerate another category that was listed more than 20 years ago,$^{40}$ namely that of joint works. However, such a category seems not to represent a real alternative under Canadian law for a CGW. As has been pointed out, ${ }^{41}$ in Canada the concept of joint works is poorly defined by legislation and courts have always managed to stay away from it.

\section{a. The author of the program}

Can the author of the original program be taken as the author of the CGW? Very few people would doubt that the drafters of this article that you are reading are not its authors but OpenOffice.org. ${ }^{42}$ However, there is a much more pragmatic consideration: what if the CGW is strongly based into the code of the computer program that generated it? Or in more legal terms, what if the CGW is a derivative work of the computer program?

The chances for the above to happen vary depending on the type of work. In the case of an algorithm that creates music by randomly analysing what is listened on the Web, it is very unlikely that in the computer-generated song there will be code pertaining to the creator program. A song is composed by musical notes, which can be expressed in digital form, but still are representations of notes. Since the song has been created by analysing the Web, that is that there were no notes or segments of songs, or anything else written in the creator program, then there is nothing copied from the latter into the former. The same rational

\footnotetext{
38 See above note 4.

CCH v. Law Society of Upper Canada [2004] 1 S.C.R. 339

40 P. Samuelson, Allocating ownership rights in computer-generated works, 47 U. Pitt. L. Rev. 1185, 1224ss

41 D. Vaver, Intellectual Property Law: Copyright, Patents, Trade-marks (Ont.: Irwin Law, 1997) at 53-54; See also Neugebauer v Labieniec 2009 FC 666.

42 This is just an example - we are not asserting that this article has been computer-generated.
} 
holds true for computer-generated drawings or poems, as long as there are no (substantial parts) of drawings or literature copied from the originator into the originated work, as well as in the case of pictures of films recorded on an automated basis, that is, where the role of the machine is that of triggering the recording or shooting the picture at the concurrence of the established condition.

However, for other types of works, and especially for software producing other software, things might be different. Under some circumstances, compiler programs could be good candidates, when the compiled code delivered by the compiler has additional content that was not in the original source code. That is to say, when the compiler, during compilation, copies substantial parts of its code into the executable. In such a case, it might be envisaged that the executable be considered a derivative of the compiler. In a situation like this the author of the compiler program might want to claim proprietary rights in the executable based on copyright law.

Nonetheless, it is well known that a derivative work is authored by the one who has modified the original and not by the author of the original. If a person creates a work constituting a derivative work of a previous one, such person is its author, not the author of the "derivated" one. Anyhow, the fact that the derivation is performed in absence of an authorisation coming from the author of the original work does not affect the issue of authorship and/or ownership. The right to create derivative works is generally reserved to the author of the original work in almost every jurisdiction, at least in all those participating at the Berne Convention..$^{43}$ If a subject without authorization violates such a rule, she might be held liable for copyright infringement -in the absence of other lawful cases where a work can be used without authorization- and she may be condemned for damages and/or injunctive relief. However, a judge will not hold that the author of the original work becomes author of the derivative. There is no legal or economic reason why such a change of authorship should happen.

Furthermore, Canadian copyright law (in contrast to those of many other countries, and most notably the U.S.) does not provide a broad and general right of derivative work ${ }^{44}$. Section 3(1) of the Canadian Copyright Act provides that "copyright ... means the sole right to produce or reproduce the work ... in any material form whatever", and then lists, amongst others, activities specific to certain type of works, undoubtedly representing derivative works ${ }^{45}$. Such wording, as the Supreme Court of Canada affirmed, "confers on artists and authors the exclusive right to control the preparation of derivative works [such as the union leaflet incorporation and multiplying the Michelin man in the Michelin case]" and thus also including the transformation (as happened in a English case) of a two dimensional cartoon character into a threedimensional doll ${ }^{46}$. However, the SCC concludes that to "the extent that [the respondent] seeks to enlarge the protection of sec. 3(1) by reading in the general words "recast, transformed or adapted" [the U.S. Copyright Act terminology] as a free-standing source of entitlement, his remedy lies in Parliament, not the courts" thereby saying that even if Canadian law recognizes a specific right of derivative work and vests it to the author of the original work, such right is limited, narrower than that of the southern neighbour ${ }^{47}$. Determining to which extent this is narrower will probably be the object of future case law.

Therefore, a CGW, if held to be a derivative work, may not in any case be firstly owned by the author of the computer program that has originated it, at least in terms of derivative work rule.

Accordingly, since the author of a derivative work is the "derivator" the possible scenarios are: if the latter is the same author of the computer program, then she is the author of both works (the author of the compiler has used it to compile the source code he has written). On the other hand, if the author of the derivative is another person, then this another person is the author (and eventually copyright infringer) of the work. Interestingly, at this regard the U.S. Copyright Act provides a peculiar provision: if the derivative work is based on an original work not lawfully used, its creator does not receive any protection. The concept of lawfulness must be kept separated from that of authorisation inasmuch as the legal bases of using an original work to create a derivative can be represented by other legal sources different from right-holder's consent:

43 Berne Convention, supra note 1 at Art. 2(3) "Derivative Works" reads: "Translations, adaptations, arrangements of music and other alterations of a literary or artistic work shall be protected as original works without prejudice to the copyright in the original work".

44 U.S. Copyright Act, supra note 12 at $\S 101$ and $\S 106$; See also House Report H.R. REP. 94-1476, 1976 U.S.C.C.A.N. 5659 [Legislative history of the Copyright Act], at sec. 5670 (Nature of Copyright).

45 Canadian Copyright Act, supra note 18 at s. 3(1) (a) deals with translations, (b) with conversions of dramatic works to novels, (c) with conversions of novels into non-dramatic works, (d) with making of sound recording or cinematographic films in the case of literary dramatic or musical works.

46 Théberge, supra note 33 at 73.

47 Idem. 
one example for all, fair use. ${ }^{48}$

Thus, in the case of CGW, if and only if the CGW possesses substantial parts of code (or theoretically other copyright material) copied form the original program, then the author of the original program remains obviously the author of that part of code present in the CGW. However the CGW in itself does not belong to him, since it may not be considered a work of the author of the computer program that have originated it. ${ }^{49}$ Under U.S. copyright legislation, for instance, it is undisputed that the intention for the derivative work category was not to cover the output of a work. ${ }^{50}$ It must be repeated that we are analysing only the ownership/authorship aspect of such a situation. Any eventual agreement between the subjects (assignment, contract, licence) or other factual or legal circumstances are not considered here.

Finally, it is barely the case to observe how recognising to the original author a need for reward, which works independently without any causational relationship to his activity, would have no incentive function, thereby frustrating any utilitarian approach.

\section{b. The user of the program.}

Although we identify a category as CGW where there is no direct human intervention, at some point a person has to intervene to supply energy, to plug in some cable, to update a DNS server, but in the initiation of a process directly connected with the creation of a new work, humans play no such relevant intervention. This is the case, for instance, where a person clicks on an icon or button in order to activate a program. Such a program may perform many different activities, which can be totally unknown to the presser of the button. Such clicking could for example activate those music generator algorithms seen above that analyses randomly all the music indexed by a search engine as "Classic" or "Jazz", and after statistical analysis it produces and plays new music. As far as this new music is prima facie music (copyright is not interested in the artistic quality of the output), it could qualify for copyright protection. Imagine also the security officer who points the security camera in the premises of the museum, or the employee of Google who establishes the time interval between one shot and the next one for the satellite taking pictures of the earth or for the car taking pictures of the streets and neighbourhoods.

However, to vest authorship in the person who has just (and sometimes unconsciously) pressed a button, without performing any other activity such as choosing the subject, the landscape, the time of the day/year, the type of light and shadows, how long the shutter should remain open, angle or any other "authorial" act, is something that might eventually give incentive for people to go around looking for good programs to exploit, but does not favour the creation of new programs, nor better music, pictures, films or maps. In this case, to reward the user of the program, could lead to a counter-intuitive consequence, that is to create an incentive for free riding, which is typical behaviour that leads to market failures in the case of informational assets, instead of the production of science and useful arts. It is understandable that by doubting the subject beneficiary of a reward, the temptation of some could be that of rewarding the human closest in the process of creating the work (accomplished exclusively by the machine). Some Copyright Acts and some scholars express this view. ${ }^{51}$ However, such temptation is not justified, as we have demonstrated that it does not represent an incentive to create more works, since they have been created by the machine and not by the human, and the machine does not work on an incentive or reward basis. It might be argued that those who have invested significant time and effort in gathering (non authorial) information still deserve some economic acknowledgement of their activity, otherwise their entrepreneurial initiatives could be frustrated. The objection is well founded, and the law puts at their disposal many different tools to protect their investments, such as trade-marks, trade-secrets, confidential information, unfair competition, privacy, and similar actions. However, such information is not creative and is not produced under the incentive and reward dialectic, therefore it does not qualify for copyright protection.

In conclusion, where there is no human intervention, as defined above, there is no incentive for giving authorship to one who has accidentally pressed a button. This approach seems to be shared by U.S. copyright law, where it is defined that "the term "authorship" implies that, for a work to be copyrightable, it must owe its origin to a human being. Materials produced solely by nature, by plants, or by animals are not

48 See U.S. Copyright Act, supra note 12 at $\$ 103(2)$.

49 See P. Samuelson, Allocating ownership rights in computer-generated works, 47 U. Pitt. L. Rev. 1185, 1224ss at 22.

50 See Legislative history of the Copyright Act, supra note 44, at sec. 103.

51 See supra note 5 and 16. 
copyrightable", ${ }^{52}$ and by Australian Copyright law, where author is defined in a human-oriented fashion, as an Australian person or Australian resident. ${ }^{53}$ Such a conclusion seems to be compatible with Canadian law and supported by some leading scholar: "Whether scenes taken by an automatic surveillance camera are authored by anyone is doubtful: the person responsible for positioning the camera is no Atom Egoyan. Such authorless films may have no copyright at all". ${ }^{54}$

\section{c. The program}

We have seen that it could be theoretically admissible to vest authorship to a computer program, at least in those jurisdictions that do not explicitly exclude this possibility, or where legislators established that the author should a person. In particular, under Canadian legislation, copyright protection in favour of computer programs could be viable, at least in those cases where computer works are not distinguishable from human works, for example in the contentious case of A.I.

However, to vest authorship to a computer program in terms of utilitarian analysis brings us to an even more obvious conclusion than that achieved when dealing with the creative requirement. If we give an incentive to a computer program, which as it is not human has no need of incentives in order to produce more works (unless it has been instructed to behave that way) who are we actually benefiting? The answer is nobody. Since to create monopolistic situations where there is no sound reason for it contradicts the basics rules of the economic theory, they should not be created. On the contrary: the creation of property rights in the absence of negative externalities to internalize has proven to be inefficient, and capable of leading to specific market failures such as free riding and anti-commons. ${ }^{55}$

At the same time, we can observe that many jurisdictions more or less explicitly require a person to be an author, ranging from the most person-oriented (civil law, where usually only physical persons may be deemed authors in connection with the strong personality-oriented type of protection offered), to the more permissive, common law systems.

\section{d. None}

The last of the identified solutions is: nobody. A basic principle of economics is to allocate scarce resources in an efficient way, that is to say in a way in which those given scarce resources are able to produce the maximum benefit for the whole society (maximization of allocative efficiency). So long as there is no subject who can be identified in terms of incentive theory as an efficient allocation, then the question becomes why should they be allocated "randomly" just for the sake of allocation, and not on the basis of any theoretical justification, being it utilitarian or naturalistic. This would produce property rights where economically speaking such a solution can be identified as inefficient, not optimal, or even worse, as leading to market failures. Market failures such as these are avoidable by falling back to a specific morphology of property rights that seems to be often overlooked as a feasible and many times more allocative-efficient solution: the Public Domain. This point seems to have been seen also by other authors "If there is no human author of the computer-generated work, the intellectual property system has assumed no one deserves to be rewarded for it. If there is no human author of such a work, how can any human be motivated to create it? [...] If it is not clearly necessary to grant the exclusive rights to stimulate creativity, traditional principles would seem to argue that the set of exclusive rights not be awarded to anyone". ${ }^{56}$

In recent time, more and more studies have demonstrated how a common domain of knowledge where everyone can resort to without the biases of being sued for copyrighted infringement by the alleged author of a work that until that very moment was an "orphan" ${ }^{57}$ is extremely important in terms of fostering the progress of a strong scientific, cultural and economic development. Other studies have tried to give a monetary value to the Public Domain broadly understood ${ }^{58}$ so including exceptions, limitations and free uses

52 See Compendium II, supra note 36 at $\$ 202.02$ (b).

53 See Copyright Act 1968 - Sec. 32 (4); See also Telstra Corporation Limited v Phone Directories Company Pty Ltd [2010] FCA 44 at 2.3.

54 D. Vaver, Intellectual Property Law: Copyright, Patents, Trade-marks (Ont.: Irwin Law, 1997) at 54-55.

55 Mark Lemley, Property, Intellectual Property, and Free Riding, (2005) 83 Texas Law Review 1031.

56 P. Samuelson, Allocating ownership rights in computer-generated works, 47 U. Pitt. L. Rev. 1185, 1224ss.

57 Yochai Benkler, The Wealth of Networks: How Social Production Transforms Markets and Freedom, Yale Univerity Press, 2006.

58 For a recent study sponsored by the Computer \& Communication Industry Association trying to calculate the 
and dealings.

Hot-topic issues in the copyright realm tend to fall around digital and Internet based issues, such as user-generated content, orphan works, terms of protection, commodification, atomisation of vested subjects, and proliferation of new rights vaguely connected with creativity and/or originality. These are problems that may be exacerbated by recognising property rights where they are not necessary. The priority here should be to avoid types of biases that, by creating legal uncertainty and raising the amount of transactive costs, stifle rather than foster innovation. Heller has demonstrated how too many property rights, especially when not precisely defined, do not contribute to more efficient internalisation of externalities, but on the contrary, due to a system of interlocking prohibitions, bring an economic good to a situation of market failure, or in other words, to its destruction..$^{59}$

Such a situation seems to be much more threatening for the socio-economic and scientific development in terms of innovation and technological growth, than that arising from the connected uncertainty regarding what part of the CGW is used by an author who creates a derivative work and may have incentives to claim full authorship over both works (not only his addition). This is basically the type of bias that drove P. Samuelson to dismiss the option of the public domain for the CGW: "it would be difficult, if not impossible, to prove what the original content of the raw output was and to reward the user only for that which he personally added to the final product [...] The result would be the same as if one gave rights to the user in the first place". ${ }^{60}$

It might be true that the author of a derivative work may have the temptation of claiming authorship over a "bigger" work (composed by the CGW and her own addition) than to just his product. It may also be true that in a situation where the CGW is "without author" there is no other subject that can resist (including judicially) such claim. But exactly for the same reason, the absence of any exclusive right, many other authors before the "egoistic" one may have used that same CGW, and in such a way that the proof of belonging to the Public Domain should be even easier to acknowledge by every participant (in patent law, mutatis mutandis, this is uncontroversial, as prior art).

That being said, in observing the development over the last 20 years on digital and telecommunication networks, the costs in terms of legal uncertainty, of incentive to litigation, of market failures seem to be connected with problems like too low originality standards, bad allocations of resources and anticommons. If this portrait is accurate, the weight of an author who tries to affirm his authorship over parts of works not created by him have so far seemed to have been aligned to the average, if not even negligible.

\section{Conclusions}

Under Canadian law the solution proposed here, that in absence of direct human intervention the work so created should belong to the Public Domain, seems to be perfectly in accordance with the general principles of the law and with the Canadian Copyright Act, further representing a much more efficient allocation of resources. There seems to be no reason why such a solution could not be implemented at the present state of legislation by courts and supported by scholars, so much that some authors apparently would welcome it. ${ }^{61}$

We have seen how other common law countries have adopted a different approach. In England the provision that in absence of direct human intervention the author should be taken to be the person who arranged the necessary steps has been applied without hesitation by courts ${ }^{62}$. New Zealand and South Africa will probably follow along the same lines since their statutory provisions leave little discretion. Australia, despite of an initial overtures along the same lines, has not transposed it into legislation, and this has allowed their courts to take a different stand. Canada has not yet expressed a direction in the courts or legislation, but

economic value of fair use - calculated in 4.4 trillion dollars in the U.S. for the year 2007 - see T. Rogers - A. Szamosszegi, Fair Use in the U.S. Economy: Economic Contribution of Industries Relying on Fair Use, (CCIA: September 2007) available online at ccianet.org.

59 Michael Heller, The Gridlock Economy: How Too Much Ownership Wrecks Markets, Stops Innovation, and Costs Lives, (New York: Basic Books, 2008).

${ }^{60}$ See P. Samuelson, Allocating ownership rights in computer-generated works, 47 U. Pitt. L. Rev. 1185, 1224ss at 1226-1227.

61 D. Vaver, Intellectual Property Law: Copyright, Patents, Trade-marks (Ont.: Irwin Law, 1997) at 55.

62 See Nova Productions Ltd v Mazooma Games Ltd \& Ors Rev 1 [2006] EWHC 24 (Ch) (20 January 2006) at 104, however we could argue about the nonchalance with which Mr. Justce Kitchin dealt with the role played by the programmer of the software and the user of the software in the creation of the CGW. 
we hope that this small contribution may help when the moment comes.

Over many centuries of history and until the 1970s, creativity and inventiveness grew harmoniously with a fair and practical balance between private and individualised benefits (property rights) counterbalanced by public and distributed benefits (public access and public domain). Recently such a balance has been disrupted due to a constant erosion of the public domain that widely distributed benefits, and granted public access to the general public. As in an equilibrium, the two opposite forces that compete must be balanced. If one crashes, it is only a matter of time for the other one to follow the same destiny. 